\title{
Design and technological aspects of spiked cereal combine stripping
}

\author{
Gennady Maslov, Elena Yudina*, Denis Ushakov, and Gavriil Samurganov \\ Kuban State Agrarian University named after I.T. Trubilin, 13, Kalinina st., Krasnodar, 350044, \\ Russia
}

\begin{abstract}
The article proposes system research of the spiked cereals harvesting process by a combine stripping, when the stripping header and the grain heap clearing are performed by one harvesting unit based on a self-propelled all-wheel drive combine harvester with a modernized design and technological scheme, in contrast to their aggregation by conventional batch-produced harvesters, which do not provide the harvesting quality according to the agrotechnical requirements. The commonly used aggregation of high-performance stripper headers by series combine harvesters, does not give an effect from the technology of combine stripping due to such violations of agrotechnical requirements as grain crushing for up to $1,9 \%$, its direct losses off the combine for up to $1,5 \%$, high kernel micro-damage, etc. With the use of a system approach, the design and technological aspects of spiked cereal combine stripping have been proposed, the use of which will eliminate the disadvantages of the used combine stripping while maintaining the high achievements of this technology in increasing labor productivity by $1,4 \ldots 2,0$ times and saving diesel fuel for up to $45 \%$. In the principles of improving the technology by combine stripping, proposed by the authors, the requirements for its subsystems are given, indicating the main parameters of the stripping header and the combine harvester that aggregates it for clearing an unwinnowed grain heap. The proposed approach will enable to accelerate the spiked cereal stripping technology implementation with a high increase in the harvesting unit performance by $1,4 \ldots 2$ 2,0 times and with a fuel economy for up to $45 \%$.
\end{abstract}

\section{Introduction}

The improvement of the grain crop harvesting technology is an urgent task of the agroindustrial complex, especially since it occupies half of the arable land. The practically ubiquitous technology of the grain crop continuous cutting has already exhausted its capabilities and requires replacement, since it is one of the costliest processes in its cultivation. In addition to high costs, the applied technology admits of large crop losses, grain injury and adversely affects soil fertility, destroying its structure with heavy harvesting equipment. To solve the problem, scientific organizations are looking for new principles of influence on the inflorescence of harvested crops, the implementation of

\footnotetext{
*Corresponding author: elena_yudina1963@mail.ru
} 
which will significantly reduce grain losses, harvesting costs and increase the harvesting machine performance. For example, in harvesting grain crops by stripping, the combine harvester performance increases 1,4 ... 2,0 times, the fuel consumption decreases to $45 \%$ [1]. However, the grain harvesting by combine stripping, having just begun its manufacturing application, already requires further improvements [1]. The process of stripping growing plants in general has been sufficiently studied in our country [1, 2, 3, 4] and abroad [5, 6, 7], however, the analysis of the operation process of stripper headers and technological schemes of combine harvesters, aggregating them, allowed to formulate new design and technological aspects of effective combine stripping, which is the purpose of the article.

At present, combine stripping is used very rarely in production. The reasons, restraining the widespread introduction of stripping, are the following: the discrepancy between the design and technological scheme of serial combine harvesters in unit with stripper headers and the structure of the stripped heap for the qualitative separation of its components and reducing grain losses; the yield loss in harvesting littered, lodged, multi-tiered crops and with uneven ripening; the wheat grain crushing for up to 1,9\% [1]; the grain losses by serial stripper headers "UKR-Agro" - for up to 1,5\% [1]. Clearing the unwinnowed grain heap at the stationary installation is also not widely used.

\section{Materials and methods}

In the studies, preparing this article, the generalization method for research results of the harvesting unit operation with stripper headers, as well as the analysis and synthesis of breakthrough directions in improving the stripping process and design solutions, have been used (Fig. 1). The applied principles of the system approach made it possible to present the harvesting unit in the form of a system with two interconnected subsystems: a stripper header, which creates an unwinnowed heap in the process of stripping, and a self-propelled combine aggregating it for high-quality clearing of this heap without a break in time.

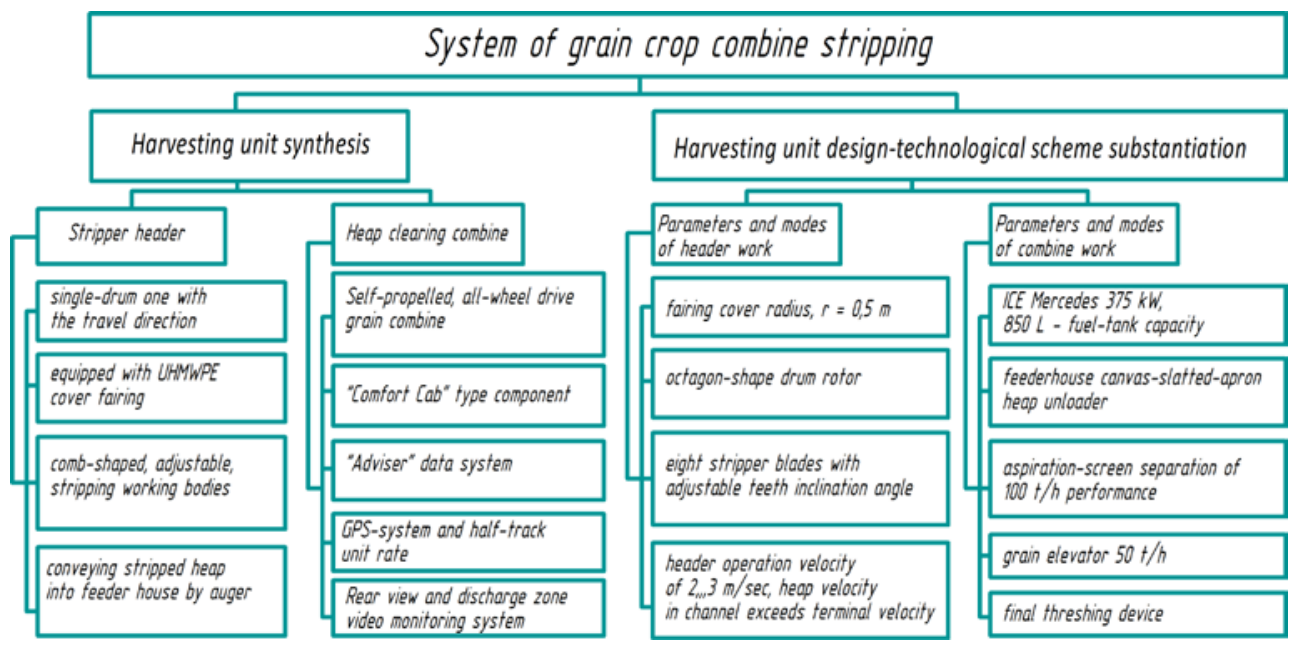

Fig. 1. The synthesis of grain crop combine stripping. 


\section{Results and discussions}

Let us imagine the technology of harvesting grain crops by combine stripping in the form of a system (Fig. 1) with two subsystems: a stripper header and a combine for clearing the stripped heap. The first subsystem considers four sections, the second one - five.

Let us consider the sections of the first subsystem. In the first of them, based on the generalization of the operation results of many stripper headers and the analysis of various existing design-technological schemes, we proposed a single-drum scheme with the drum rotating in the travel direction (Fig. 1). This circuit is simple in design, less metal consuming and in terms of work quality is not inferior to the more complex and expensive two-drum circuit. The second decision has been made on the basis of the research results of I.V. Chervyakov [1]. The header body fairing cover with ultrahigh molecular weight polyethylene (UHMWPE) provides a reduction in the frictional force of the spike when it moves while working on the fairing surface, as a result of which the harvesting unit can operate at a higher speed than with a fairing body made of steel without UHMWPE coating. The author established the friction forces of the spike against the fairing material at a speed of $3 \mathrm{~m} / \mathrm{s}$ : for a steel body, the friction force was 3,51 N, and for coated UHMWPE - 2,0 N [1]. It can be concluded that with a grain-to-spike bond force of 2,14 $\mathrm{N}$, it is possible to operate at a speed of $3 \mathrm{~m} / \mathrm{s}$ without yield losses with a fairing body covered with UHMWPE. Uncoated fairing bodies can only be operated at a speed of $2 \mathrm{~m} / \mathrm{s}$ to avoid grain loss. Thus, only by covering the fairing with UHMWPE coating it is possible to increase the header performance at the expense of speed.

In the used harvesting units with combine stripping, the stripped heap is supplied for clearing according to the type of work of the continuous cut header, i.e. with the header auger into the feederhouse through a spacer and then the chain-slat conveyor of the feederhouse delivers the heap into the threshing unit. Such a scheme cannot be considered rational because of its cumbersomeness and grain injury. We propose to deliver the heap stripped by the header to the canvas-slat conveyor of the feederhouse with its subsequent transportation to the high-performance aspiration-screen clearing (Fig. 1). This will reduce grain injury and loss, as in the case in practice in a widely used technological scheme. In using stripper headers with serial harvesters, the heap with already threshed grain is again delivered into the threshing unit, the grain is injured, clearing is overloaded, and losses increase. Only the final threshing device and the grain elevator can be left unchanged.

The second subsystem - a combine for heap clearing (Fig. 2), considers five sections. In the first one, for the harvesting unit, a self-propelled all-wheel drive combine harvester with a modernized technological scheme is proposed. Some of the requirements for the unit in subsystem 2 are well-known. This pertains to equipping the cab with the "Comfort Cab" system, the "Adviser" data system, the GPS navigation system, the rear view videomonitoring system and the grain discharge zone, the system of the interchangeable halftrack harvester. All of these systems make it easier to operate the unit, increase its performance, and the replaceable track - to reduce soil compaction.

The subsystem for substantiating the design and technological scheme of the harvester unit (Fig. 2) includes the substantiation of the stripper header scheme and the combine that aggregates it. In justifying the header parameters, it is necessary to consider the design and operating parameters already justified and proven by practice. This refers to the header fairing cover radius, which is $0,5 \mathrm{~m}$, stripper drum in the form of an octagon [1], eight stripper blades with teeth, in which the inclination angle is adjusted in the range of $0,3 \ldots$ 0,7 radians for different lodging of the grain mass and layering. The header speed is taken in the range of $2 \ldots 3 \mathrm{~m} / \mathrm{s}$, depending on the force of separation of the grain from the spike and the friction force of the movement of the spike along the fairing of the header with or without UHMWPE coating. Scientific research has substantiated the average velocity of 
grain movement in a heap, considering all its components, and it should exceed the terminal velocity value in order to prevent grain losses during its movement along the transporting channel to the integrating auger.

To select the combine parameters aggregating the stripper header, the grain crop harvesting time, the unit high performance, the cost and loss reduction are considered. For large agricultural enterprises, a harvester with an internal combustion engine (ICE, Fig. 2) Mercedes with a capacity of $375 \mathrm{~kW}$ and a fuel tank capacity of 850 liters, is chosen. To reduce grain injury, a canvas-slat conveyor for the header heap (Fig. 2), aspiration-screen clearing of the heap with a capacity of at least $100 \mathrm{t} / \mathrm{h}$, an elevator for feeding clear grain into the hopper and a final threshing device are equipped in the combine feederhouse.

Based on many years of research, we have developed the design-technological schemes for many promising machines and units, considering the agricultural requirement fulfillment [8], allowing the introduction of new energy-saving technologies [10], reducing costs due to parameters optimization [11]. For example, Figure 2 shows one of them. This is a diagram of a combine unit for grain crop harvesting by stripping growing plant. This technology has been developed for a long time, but has not received widespread practical application due to increased injury and grain loss. The modernized scheme of the combine proposed by us will eliminate the mentioned disadvantages.

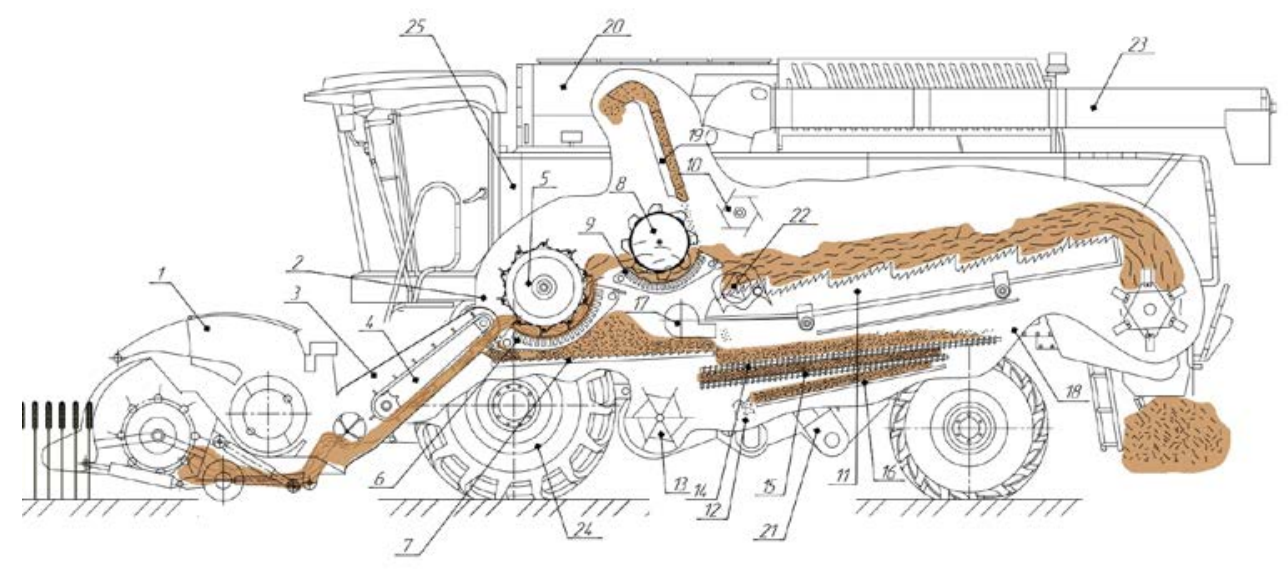

Fig. 2. The combine design-technological scheme.

There are many different design-technological schemes of harvesting units for grain harvesting by combine stripping, but considering their advantages and disadvantages, we have chosen a harvester for the prototype according to the patent of the Russian Federation for invention № 2541655 [9]. The prototype disadvantages are that the harvester has a complex design, the absence of a straw stripper and straw walker in the scheme is fraught with increased grain losses. The harvesting unit design-technological scheme, proposed by us, includes a header 1 for stripping and threshing growing crops, hung on a combine thresher 2 using a feederhouse 3 with a conveyor 4 for stripped heap, a rotary-pin receiving beater 5 with a rod-slatted deck 6, a shaker board 7, a threshing drum 8 of a beater type with a rod-slatted deck 9 , a straw stripper 10 , a straw walker 11 , a heap clearing 12 with a fan 13, a top 14 and bottom 15 sieves and a grain board 16, a fan 17 for removing chaff and small straw particles from under the straw walker 11 into the outlet opening 18 of a thresher 2 , a grain elevator 19 , a hopper 20 , a return elevator 21 , a final threshing device 22 , an unloading auger 23, an undercarriage 24 and a motor unit 25.

The grain crop harvester by combine stripping works as follows. When the combine moves across the field with a grain mass, the header 1 , suspended on the thresher 2 with the 
help of the feederhouse 3, combs and threshes the spikes of the harvested crop. The stripped heap is delivered by the conveyor 4 of the feederhouse 3 to the receiving beater 5 of the thresher 2 . The rotary-pin receiving beater 5 pulls the heap into the gap between it and the deck 6, while free grain is separated through the outlet openings in the deck 6 onto the shaker board 7 . The deck outlet openings 6 , made with the possibility of adjusting their width with dimensions 0-1 / 2-1 (i.e., closed, half open, fully open). This adjustment is carried out by rearranging the rods into the round holes of the deck 6 crossbars. Through the deck 6 outlet openings, the grain entering it from the heap is separated up to $30 \%$. This advantage of the proposed harvester reduces grain injury and thus its indirect losses.

Next, the heap from the deck 6 enters the gap between the threshing drum 8 and its deck 9. The drum beaters 8 , the pin fingers of the receiving beater 5 and the conveyor strips 4 of the feederhouse 3 are made of durable ultra-high molecular weight polyethylene, which, unlike metal-like in the prototype, also reduces injury to the grain and thereby improves its quality. Deck 9, as well as deck 6, is rod-slatted with the possibility of adjusting the width of the outlet openings for separating grain onto the shaker board 7. The threshing drum 8 threshes the grain from the spikes and their fragments, contained in the heap, and directs the threshed heap to the straw stripper 10 , which, reducing its speed after drum 8 , directs the heap to the beginning of the straw walker 11 . The latter is also necessary, unlike the prototype, since when the heap moves along the keys, the heap speed and grain loss decrease. The design feature of the straw walker from the serial one is the elimination of its bottom. Therefore, the grains are separated immediately for clearing 12 with a fan, passing through the louvers in the upper part of the straw walker 11. To prevent small fractions of straw and chaff, spilling through the straw walkers 11, from falling on the upper 14 and lower 15 clearing sieves and from not worsening the grain separation, the fan 16, creating an air flow for the removal of chaff and straw particles into the opening 18 of the thresher 2 on the field, is fixed under the straw rack.

Part of the grain heap, spilled through the decks 6 and 9 outlet openings, enters the shaking board 7 and, thanks to its oscillatory movements, the grain tends to take the desired position, and the unmilled spikelets - the top one. Having reached the upper sieve 14, the grain heap is exposed to the fan 17 air flow for combine clearing 12. Rare impurities and chaff are blown out into the combine outlet opening 18.

Grain and half-milled spikes fall through the upper sieve 13 louvers and enter the lower sieve 15 surface of the sieve boot 12 with a pitched board 18. Clear grain falls through the lower sieve 15 of the sieve boot 12 and along the pitched board 18 enters the grain elevator 19 and further into the hopper 20 for collecting cleared grain, installed on the combine frame.

Under-threshed spikes leave the lower cleaning 12 sieve 15 and enter the return elevator 21 for transporting them to the final threshing device 22, where the spikes are threshed, and this heap is delivered to the shaking board 7 working surface and then to the upper sieve 14 of cleaning 12, then the lower 15 falls on the sloping board 18, in the grain elevator 19 and the hopper 20. Clean grain from the filled hopper 20 is unloaded by the auger 23 into the vehicle.

The drive of the working bodies and the undercarriage 24 of the combine is carried out from the motor unit 25 .

\section{Conclusions}

As a result of the research conducted, the authors proposed a systemic solution for the grain crop harvesting process by a combine stripping, in which the harvesting unit is represented by two subsystems - a stripper header and a modernized combine for clearing a heap. The proposed design-technological scheme of the harvesting unit, retaining the advantages of 
stripping technology in terms of productivity growth by $1,4 \ldots 2,0$ times, fuel saving up to $45 \%$, will provide direct grain losses of no more than $1,5 \%$ of the harvest, including behind the combing header 0,47 [1]. The combine that aggregates the stripper header, in contrast to the serial one, must be modernized in accordance with the proposed recommendations: the use of ultra-high molecular weight polyethylene for the production of the feederhouse conveyor slats and the threshing drum beaters, the rotary-pin receiving beater, the receiving beater decks and a drum with an adjustable window opening area to optimize the combine clearing load.

\section{References}

1. I.V. Chervyakov, Improving the process of harvesting grain crops by combine stripping. Abstract dissertation. for the degree of candidate of technical sciences // Rostov-on-Don, Gagarin square, 1, FSBEI HE DSTU (2021)

2. S.D. Ridniy To the question of harvesting grain by combing growing plant / S.D. Ridny, A.Yu. Fustochenko // Bulletin of the Mountain State Agrarian University. 1-2, 244-245 (2012)

3. P.A. Shabanov, Determination of the dependence of some parameters of the stripping device on the state of the stalk. Complex mechanization and automation of agricultural production: collection of articles / RISHM. - Rostov-on-Don. (1978)

4. F.V. Kovlyagin, G.G. Maslov, Cleaning grain crops by stripping method, Mechanization and electrification of agriculture. 8, 5-6 (1991)

5. S.R. Patel, B.P. Varshney, Modeling of wheat crop harvesting losses. Agricultural Engineering International: CIGR Journal. 16 (2), 97-102 (2016)

6. C.J.M. Tado, P. Wacker, H. D. Kutzbach, D.C. Suministrado, Development of Stripper Harvesters. A. Reviev. Journal of Agricultural Engineering Research. 71 (2) 103-112 (1998)

7. J. Ynan, Y. Lan, Development of an improved Cereal Stripping Harvester. Agrie Eng Int: CLOR Journal. 9 1-12 (2007)

8. Rybalkin P.N., Vasyukov P.P., Sokht K.A., Shcherbina P.A. and others, Agrotechnical requirements for the main technological operations with adaptive technologies for the cultivation of winter crops and maize and new technical means for their implementation in the Krasnodar Krai. Recommendations / Department of Agriculture and Food of the Krasnodar Krai, KNIISH named after P.P. Lukyanenko. - Krasnodar, (2001)

9. M.V. Kandelya, N.M. Kandelya, P.A. Shilko, P.V. Berezovskiy, A.N. Panasyuk, A. V. Lipcan, Patent № 2541655 RF MPK A01.D 41/08. Combine for harvesting grain crops by stripping, applicant and patentee: GNU DalNIIMESKH Russian Agricultural Academy № 2013142011/13; Application. - 09/13/2013; Published on February 20, 2015. Bul. 5, 8 p.

10. G.G. Maslov, V.T Tkachenko, E.M Yudina, M.R. Kadyrov, S.A. Kalitko The Improvement Of The Technology Of Winter Wheat Grain Production For The Purpose Of Energy Saving. Biosci Biotechnol Res Asia; 12 (3) 2071-2080 (2015)

11. G.G. Maslov, E.I. Trubilin, E.V. Truflyak, Parameters Optimization for Multifunctional Aggregates in Plant Growing Mechanization. Res. J. Pharm., Biol. Chem. Sci. 7 (3) 1919-1926 (2016) 